\title{
Deprivation, ethnicity and the prevalence of intellectual and developmental disabilities
}

\author{
Eric Emerson
}

- Additional tables are published online only. To view these files please visit the journal online (http://jech.bmj. com/content/66/3.toc).

Centre for Disability Research, Lancaster University, Lancaster, UK; and University of Sydney, Sydney, Australia

\section{Correspondence to}

Professor Eric Emerson, Centre for Disability Research, Lancaster University, Lancaster, LA1 4YT, UK:

eric.emerson@lancaster.ac.uk

Accepted 4 August 2010 Published Online First 1 October 2010

\begin{abstract}
Background Social gradients and ethnic disparities have been reported in some forms of intellectual and developmental disabilities. However, information on the association between area deprivation, ethnicity and other forms of intellectual and developmental disabilities are inconclusive.
\end{abstract}

Aim To estimate the independent association between household disadvantage, local area deprivation, ethnicity and the identification of intellectual and developmental disability.

Methods Cross-sectional survey involving multilevel multivariate analyses of data extracted from educational records on household disadvantage, local area deprivation, ethnicity and identified intellectual and developmental disability in a sample of English children aged $7-15$ years ( $n=5.18$ million).

Results Lower household socio-economic position was associated with increased rates of identification of intellectual and developmental disabilities especially less severe forms of intellectual disability. Higher area deprivation was independently associated with increased rates of identification of less severe forms of intellectual disability but decreased rates of identification of profound multiple intellectual disability and autism spectrum disorder. Minority ethnic status was, in general, associated with lower rates of identification of intellectual and developmental disabilities. Exceptions to this general pattern included higher rates of identification of less severe forms of intellectual disability among Gypsy/Romany and Traveller children of Irish heritage, and higher rates of identification of more severe forms of intellectual disability among children of Pakistani and Bangladeshi heritage.

Conclusions Children whose development is already compromised (and especially children with less severe intellectual disabilities) are at increased risk of exposure to social conditions that are themselves inimical to healthy development.

\section{INTRODUCTION}

The term intellectual and developmental disabilities (I/DD) has recently emerged as a term of preference to refer to the International Classification of Disease 10th revision (ICD-10) categories of mental retardation (F70-79) and pervasive developmental disorders (F84), the latter including autism spectrum disorder (ASD). The estimated prevalence of $I / D D$ is approximately $3-4 \%$ for children in high income countries, ${ }^{1-3}$ although much higher rates have been reported in some studies. ${ }^{4}$ Intellectual and developmental disabilities are associated with increased mortality and morbidity, increased risk of social exclusion, and significant demands on families and health and social care agencies. ${ }^{5} 6$ The lifetime costs to health and social care agencies of an individual with autism has been estimated at $£ 2.4$ million. $^{7}$

Previous studies have reported social gradients and ethnic disparities in the prevalence of some forms of I/DD. In particular, lower household socio-economic position (SEP) has frequently been reported to be associated with a marked increase in the prevalence of mild intellectual disability. ${ }^{1-3} 8-13$ However, the association between SEP and risk of more severe intellectual disability is less clear. While the majority of studies have reported no significant association, ${ }^{1-3}$ 11-13 others have reported that lower household SEP is also associated with an increased prevalence of severe intellectual disability, although the strength of the association is typically weaker than for mild intellectual disability. ${ }^{14} 15$ There is some very limited evidence from studies to suggest inverse social gradients in the administrative prevalence of pervasive developmental disorders with higher rates reported among higher SEP families. ${ }^{16-18}$ However, the current consensus suggests that this association is likely to reflect ascertainment bias in health and social care agencies rather than any social gradients in true prevalence. $^{16-19}$

Household SEP tends to be geographically clustered resulting in local geographical areas or neighbourhoods being characterised by differing levels of deprivation. ${ }^{20}$ A growing body of research has focused on the effects on health and well-being of neighbourhood deprivation over and above any effects attributable to rates of household deprivation within areas. ${ }^{21}$ While no study, to date, has investigated the independent association between neighbourhood deprivation and I/DD, the existing literature does suggest that neighbourhood level deprivation may have an impact on child cognitive development over and above any effects attributable to rates of household deprivation within any given areas. $^{22}$

Limited evidence also suggests that there may be associations between ethnicity and the prevalence of I/DD. For example, previous studies have reported (1) higher rates of more severe intellectual disability among some South Asian groups in the $\mathrm{UK}^{23}{ }^{24}$ (2) higher rates of less severe intellectual disability among African-American US children ${ }^{15} 25$ and indigenous Australians; ${ }^{826}$ and (3) higher rates of pervasive developmental disorders in AfricanAmerican US children ${ }^{18} 27$ and Afro-Caribbean British children. ${ }^{28}$ However, there is an association between membership of many, though not all, minority ethnic groups in England and deprivation at either household or area level. For example, 
between 2005 and 2008 the median household income (adjusted for household composition and before deduction of housing costs) of Bangladeshi or Pakistani households in the UK was $£ 238$ per week; $42 \%$ less than that of White households. ${ }^{20}$

One critical aspect of research in this area is to attempt to estimate the independent effects attributable to household deprivation, neighbourhood characteristics and ethnicity. To date, no studies have attempted to do this. Research in this area is also beset by a number of additional problems, including small and possibly unrepresentative sample sizes, and variation in, and unknown reliability of, case ascertainment methods. The aim of the present paper is to investigate the association between household SEP, area-level deprivation, ethnicity and the identification of I/DD in a near complete sample of English children aged $7-15$ years.

\section{METHODS}

\section{Sample}

Data were extracted from the English Spring 2008 School Census. The School Census is undertaken by the English Government Department for Education each school term (three each year) and collects information on all children enrolled in all English statefunded schools and non-profit making independent special schools during that term (http://www.teachernet.gov.uk/ management/ims/datacollections/sc2009/). Schools have a statutory responsibility to return Schools Census data under section 537A of the Education Act 1996. Given that overall rates of identification of special educational needs (SENs) show a sharp rise in the younger age ranges and then plateau from age 7 years onwards, ${ }^{29}$ the sample was restricted to children in the age range $7-15$ years (age 15 being the last year of compulsory education in the UK). The Spring 2008 School Census contained information on 5180550 children in this age range $(97.2 \%$ of the estimated total population of English children in that age range). ${ }^{\mathrm{i}}$ Children not included in the School Census include children being educated at home and children educated in independent (non-state funded) mainstream schools and profit-making independent special schools. Approval for use of these administrative data was granted by the Department for Education.

\section{Measures}

Intellectual and developmental disability

The School Census contains information on whether a child has been identified as having SENs and, if so, the stage of assessment of SEN and the nature of the identified SEN. ${ }^{29-32}$ Stage of assessment is recorded at two levels. The lower level (School Action Plus) requires that the child has been identified by the school as having SENs and that the school's SENs co-coordinator and an external professional (eg, an educational psychologist) has been involved in the process of identification. The higher level involves the child having a formal Statement of SEN-a process that identifies the child's entitlements to specific support in the education system. The nature of the child's SEN is recorded against a predetermined series of categories. Three of these categories (moderate learning difficulties (MLDs), severe learning difficulties (SLDs) and profound multiple learning difficulties (PMLDs)) refer to different levels of severity of intellectual disability and one (autistic spectrum disorder (ASD)) relates to pervasive developmental disorders. ${ }^{31}$ For each child, up to two categories of SEN can be recorded (primary, secondary). Of the children aged 7-15 years in the 2008 Spring School

i http://www.statistics.gov.uk/StatBase/Product.asp?vlnk=539
Census, 248628 (4.8\%) were identified at School Action Plus or with a Statement of SEN identified and having SENs associated with I/DD. Altogether, 104503 of these children had a Statement of SEN $(2.0 \%$ of the total sample; $42 \%$ of the sample of children identified with SENs associated with I/DD).

\section{Household SEP}

The School Census contains one indicator of household-level $\mathrm{SEP}$ - whether the child is eligible for free school meals (FSMs). Eligibility for FSMs is determined by data linkage to government records of receipt of one of six means-tested welfare benefits by the child's parent(s). It should be noted that this indicator is of eligibility for, not uptake of, free school meals. Of the children aged 7-15 years in the 2008 Spring School Census, 800336 $(15.4 \%)$ were identified as being eligible for FSMs. As expected given the association between younger child age and child poverty, ${ }^{33}$ rates of eligibility for FSMs systematically declined with child age from $17.1 \%$ among 7 -year-olds to $12.6 \%$ among 15 -year-olds.

\section{Area deprivation}

The School Census is linked through the postal code of the child's residence to the Income Deprivation Affecting Children Index (IDACI). ${ }^{34}$ IDACI scores are the percentage of children in each Lower Level Super Output Area (LSOA) that live in families that are considered income deprived. Income deprivation is defined by receipt of means-tested welfare benefits. LSOAs are neighbourhoods with an average population of 1500 (range 1000-3000). IDACI scores were transformed into national deciles for the analyses reported below. As expected given the geographical clustering of household-level poverty, ${ }^{33}$ rates of eligibility for FSMs systematically declined with reduced area deprivation from $42.2 \%$ in the most deprived decile to $1.5 \%$ in the least deprived decile.

\section{Ethnicity}

Child ethnicity is recorded in the School Census against a predetermined series of 18 categories. Ethnicity of the children aged 7-15 years in the 2008 Spring School Census was recorded as White British (78.2\%), Pakistani (3.1\%), Other White Background (3.1\%), African (2.5\%), Indian (2.3\%), Caribbean (1.4\%), Bangladeshi (1.3\%), White and Black Caribbean (1.2\%),; Other Mixed Background (1.2\%), Other Asian Background (1.1\%), Other Background (1.1\%), White and Asian (0.7\%), Other Black Background $(0.5 \%)$, Irish $(0.4 \%)$, Chinese $(0.4 \%)$, White and Black African $(0.3 \%)$, Gypsy/Romany $(0.1 \%)$ and Traveller of Irish heritage $(0.1 \%)$. As expected given the association between ethnicity and household-level poverty, ${ }^{33}$ rates of eligibility for FSMs were higher in certain minority ethnic groups. Particularly high rates of FSM eligibility were observed among children of Traveller of Irish heritage (58\%), Gypsy/Romany (42\%), Bangladeshi (41\%) and African (40\%) heritage. Lower than average rates of FSM eligibility were observed among children of White British (12\%), Chinese (10\%) and Indian (10\%) heritage.

\section{Approach to analysis}

While national guidance exists in relation to the process of identifying SENs, ${ }^{30-32}$ it is the responsibility of each of the 150 local government areas in England to implement this guidance. Given possible variation in policy implementation across local government areas (and the clustering of children within local government areas), multilevel logistic regression was used to analyse the association between household SEP, area-level deprivation and ethnicity, and the identification of I/DD while 
controlling for clustering by local government area. Models were fitted using the xtlogit routines in Stata 10. ${ }^{35}$

Analyses were undertaken for each type of SEN (regardless of stage of assessment - that is, combining SEN identified at School Action Plus and formal Statement of SEN), for each type of SEN for children with a formal Statement of SEN and separately for boys and girls with each type of SEN (regardless of stage of assessment). Given the associations between ethnicity, household deprivation and area deprivation (see above), multivariate analyses were conducted in which the effects of each variable were estimated while simultaneously controlling for the effects of all other variables in the model.

\section{RESULTS}

The overall prevalence of SEN associated with I/DD is presented in table 1. Tables 2 and 3 present the results of the multilevel logistic regression analyses. These analyses are undertaken for each type of SEN (regardless of stage of assessment) (table 2) and for each type of SEN for children with a formal Statement of SEN (table 3). Full tables of analyses stratified by gender are available at http://jech.bmj.com

With regard to household SEP, the results in table 2 indicate that, when controlling for effects attributable to child age, gender, ethnicity and area deprivation, children who were eligible for FSMs were significantly more likely to be identified with all types of I/DD. However, the strength of the association was markedly higher for MLD $(\mathrm{OR}=2.34)$ and $\mathrm{SLD}(\mathrm{OR}=2.42)$ than for PMLD $(\mathrm{OR}=1.81)$ and ASD $(\mathrm{OR}=1.30)$. Nevertheless, when controlling for all other variables in the model, the odds that a child would be identified as having ASD was still $30 \%$ greater $(O R=1.30)$ among children who were eligible for FSMs. A similar pattern of results was observed when analyses were restricted to children with formal Statements of SEN (table 3) and when analyses were stratified by gender. In all analyses, the strength of the association between FSM eligibility and SEN declined as the severity of intellectual disability increased and was weakest for ASD.

With regard to area deprivation, the results in table 2 indicate (when controlling for all other variables in the model) a positive (approximately linear) association between extent of area deprivation and rates of identification of MLD and SLD, although the strength of the association is markedly stronger for MLD. However, no such pattern is evident for PMLD and ASD. Rather, rates of identification are significantly lower in the most deprived decile of area deprivation. Again, a similar pattern of results was observed when analyses were restricted to children with formal Statements of SEN (table 3). However, in these analyses: (1) the strength of association between area deprivation and rates of identification of MLD and SLD was markedly

Table 1 Identification of special educational needs (SENs) associated with intellectual and developmental disabilities in English school children aged $7-15$ years (base $n=5180550$ )

\begin{tabular}{lll}
\hline Type of SEN & $\begin{array}{l}\text { School Action Plus } \\
\text { or Statement of SEN }\end{array}$ & $\begin{array}{l}\text { Statement } \\
\text { of SEN }\end{array}$ \\
\hline Moderate learning difficulties (MLD) & $3.6 \%$ & $1.0 \%$ \\
Severe learning difficulties (SLD) & $0.5 \%$ & $0.4 \%$ \\
$\begin{array}{l}\text { Profound multiple learning difficulties } \\
\text { (PMLD) }\end{array}$ & $0.1 \%$ & $0.1 \%$ \\
Autism spectrum disorder (ASD) & $0.8 \%$ & $0.6 \%$ \\
$\begin{array}{l}\text { Any intellectual disability } \\
\text { Any intellectual or developmental }\end{array}$ & $4.1 \%$ & $1.5 \%$ \\
disability (I/DD) & $4.8 \%$ & $2.0 \%$ \\
\hline
\end{tabular}

attenuated; while (2) the strength of association between areas of high deprivation and low rates of identification of PMLD and ASD was markedly strengthened with this effect being apparent in the bottom two deciles of area deprivation.

With regard to ethnicity, the results in table 2 indicate that (when controlling for all other variables in the model) 30 of the $37(81 \%)$ statistically significant results indicate lower rates of identification among minority ethnic groups. This is particularly evident for MLD and ASD. Exceptions to this general pattern are (1) higher rates of MLD and SLD among Gypsy/Romany and Traveller children of Irish heritage, and (2) higher rates of SLD and PMLD among children of Pakistani heritage and of PMLD among children of Bangladeshi heritage. Again, a similar pattern of results was observed when analyses were restricted to children with formal Statements of SEN (table 3).

\section{DISCUSSION \\ Principal findings}

Multilevel multivariate analyses on a nearly complete sample of English children aged 7-15 years indicated that: (1) lower household SEP was associated with increased rates of identification of intellectual and developmental disabilities, especially less severe forms of intellectual disability; (2) higher levels of area deprivation were associated with increased rates of identification of less severe forms of intellectual disability but decreased rates of identification of profound multiple intellectual disability and ASD; (3) while minority ethnic status was, in general, associated with lower rates of identification of intellectual and developmental disabilities, exceptions to this general pattern included higher rates of identification of less severe forms of intellectual disability among Gypsy/Romany and Traveller children of Irish heritage, and higher rates of identification of more severe forms of intellectual disability among children of Pakistani and Bangladeshi heritage.

\section{Strengths and limitations of the study}

The main strengths of the study are (1) the use of an extremely large national sample of children with almost complete population coverage for the chosen age range; (2) data linkage to robust indicators of household SEP and area-level disadvantage; and (3) the use of an age-range ( $7-15$ years) in which it is likely that all children with I/DD would have been identified by education services. The main limitations of the study are (1) the unknown validity of SEN ascertainment and coding, (2) the cross-sectional nature of the design and (3) the limited information available regarding household and family characteristics.

While there exists clear and extensive guidance to schools regarding the identification and coding of SENs associated with $\mathrm{I} / \mathrm{DD},{ }^{30-32}$ no formal evaluation has been undertaken to determine the validity of the system against 'gold standard' diagnostic procedures. This is a concern given the evidence to suggest that the correspondence between administrative ascertainment and clinical testing can be far from optimal. ${ }^{4} 19$ Nevertheless, several strands of evidence support the robustness of the data used. First, as noted above, schools are provided with clear and extensive guidance regarding the identification and coding of SEN associated with I/DD. ${ }^{30-32}$ Second, Statements of SEN almost always require the involvement of accredited external professionals (eg, educational psychologists, paediatricians). Third, the overall identification rates for mild and severe intellectual disability and for ASD are consistent with the results of previous research. ${ }^{1-3} 56161719$ Finally, variation in the identification rates are largely consistent with the results of previous research in indicating strong associations between SEP 
Table 2 Association between age, gender, household SEP, area deprivation, ethnicity and identification of SEN associated with intellectual and developmental disability at school action plus level or above in English school children aged $7-15$ years ( $N=5095504)$

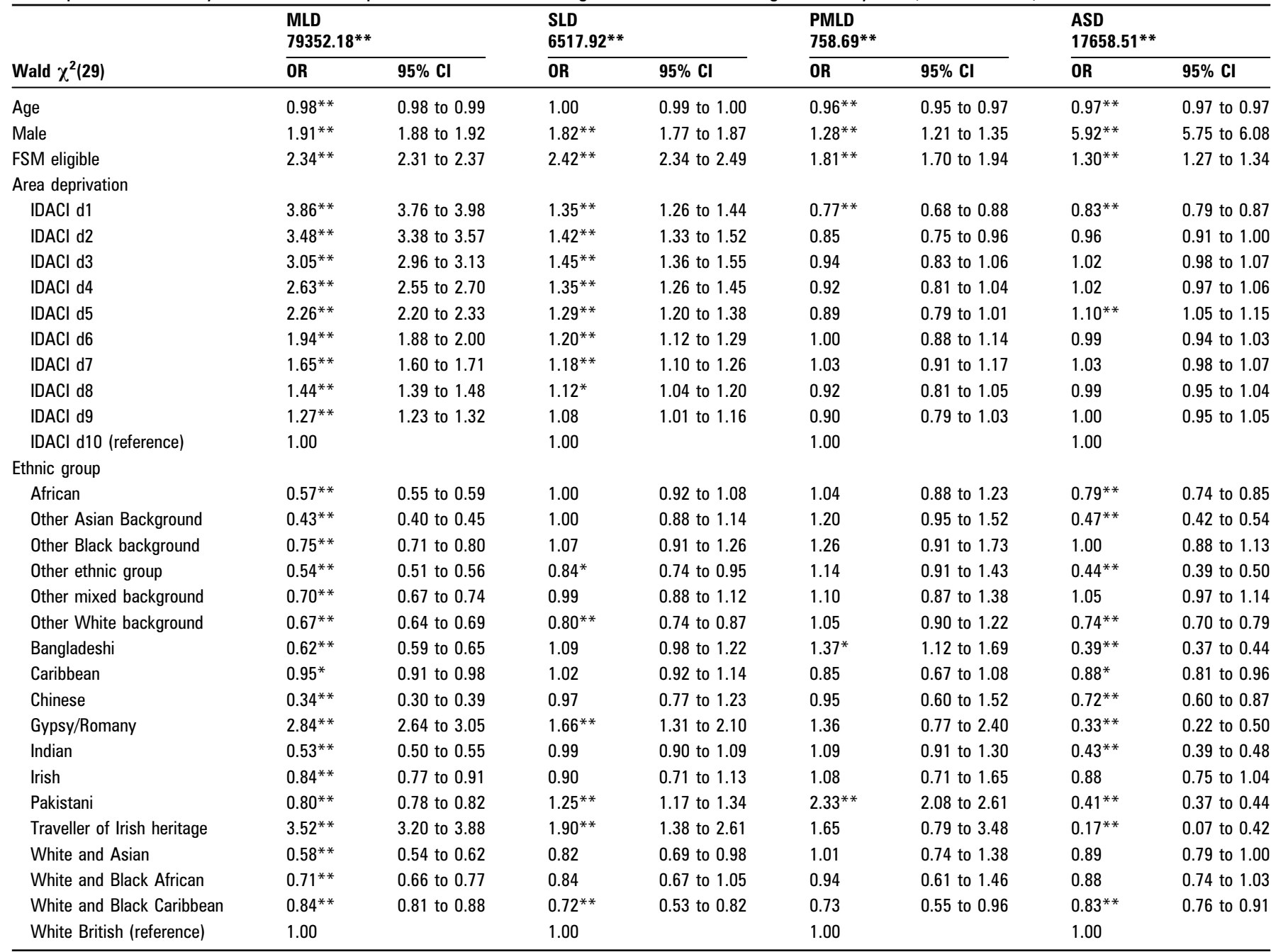

${ }^{*} \mathrm{p}<0.01 ;{ }^{* *} \mathrm{p}<0.001$.

ASD, autism spectrum disorder; FSM, free school meals; IDACI, Income Deprivation Affecting Children Index; MLD, moderate learning difficulties; PMLD, profound multiple learning difficulties; SEN, special educational needs; SEP, socio-economic position; SLD, severe learning difficulties.

and less severe intellectual disabilities and between male gender and ASD. ${ }^{1-3} 56161719$ The cross-sectional nature of the design obviously imposes severe limitations on the identification of any causal pathways that may underlie the observed associations. Finally, while it would have been preferable to employ multiple indicators to capture the complex nature of the key independent variables such data were not available. For example, other indicators of household SEP (eg, equivalised household income, hardship, patterns of adult employment) and related family characteristics (eg, parental education and IO) may have helped decompose the key aspects of poorer households that were associated with increased rates of identification of I/DD. Similarly, the availability of indicators of the multiple facets of ethnicity (eg, group affiliation/assimilation, religion, exposure to racism) may have helped decompose the key aspects of minority ethnic status that were associated with increased rates of identification of I/DD. ${ }^{36}$

\section{Meaning of the study}

The association between the identification of SENs associated with intellectual and developmental disabilities and lower household SEP and greater area deprivation suggests that children whose development is already compromised (and especially children with less severe intellectual disabilities) are at increased risk of exposure to social conditions that are themselves inimical to healthy development. ${ }^{37-43}$ As such, children with I/DD make up a disproportionate proportion of the population of children who are 'at risk' of poor health. While few studies have attempted to estimate the extent to which the poorer health outcomes experienced by children with I/DD may be attributable to their increased risk of exposure to socio-economic disadvantage (rather than impairment specific factors), the results of this nascent literature suggest that increased risk of exposure to socio-economic disadvantage may account for: $20-50 \%$ of the risk of poorer mental and physical health among children with intellectual disabilities ${ }^{44-47}$ and most or all of the risk of poorer mental health and low rates of well-being among mothers of children with intellectual disabilities. ${ }^{48}$

While, as noted above, the cross-sectional design of the study precludes drawing causal inferences, the data are consistent with the existing literature suggesting that these social gradients in childhood are likely to reflect two processes. First, exposure to socio-economic adversity (and associated material and psychosocial hazards) prenatally and in the early years impairs cognitive development and will consequently increase the incidence of I/DD. ${ }^{41}{ }^{42}$ Second, the heritability of general cognitive ability, 
Table 3 Association between age, gender, household SEP, area deprivation, ethnicity and identification of SEN associated with intellectual and developmental disability with a Statement of SEN in English school children aged 7-15 years ( $N=5095504)$

\begin{tabular}{|c|c|c|c|c|c|c|c|c|}
\hline Wald $\chi^{2}(29)$ & \multicolumn{2}{|c|}{$\begin{array}{l}\text { MLD } \\
30825.31 * *\end{array}$} & \multicolumn{2}{|c|}{$\begin{array}{l}\text { SLD } \\
5500.00^{* *}\end{array}$} & \multicolumn{2}{|c|}{$\begin{array}{l}\text { PMLD } \\
701.44^{* *}\end{array}$} & \multicolumn{2}{|c|}{$\begin{array}{l}\text { ASD } \\
13033.03 * *\end{array}$} \\
\hline Age & $1.16^{* *}$ & 1.16 to 1.16 & $1.02^{* *}$ & 1.02 to 1.03 & $0.97 * *$ & 0.96 to 0.98 & $0.98^{* *}$ & 0.98 to 0.99 \\
\hline FSM eligible & $2.60^{* *}$ & 2.55 to 2.66 & $2.45^{* *}$ & 2.37 to 2.53 & $1.81^{* *}$ & 1.69 to 1.93 & $1.36^{* *}$ & 1.32 to 1.40 \\
\hline \multicolumn{9}{|l|}{ Area deprivation } \\
\hline IDACl d1 & $2.90^{* *}$ & 2.76 to 3.05 & $1.22^{* *}$ & 1.13 to 1.31 & $0.76^{* *}$ & 0.66 to 0.86 & $0.78^{* *}$ & 0.74 to 0.83 \\
\hline IDACI d4 & $2.27^{* *}$ & 2.16 to 2.39 & $1.23^{* *}$ & 1.15 to 1.32 & 0.90 & 0.79 to 1.03 & 0.99 & 0.94 to 1.04 \\
\hline IDACI d5 & $1.99^{* *}$ & 1.89 to 2.10 & $1.20^{* *}$ & 1.12 to 1.29 & 0.89 & 0.78 to 1.01 & $1.09^{* *}$ & 1.04 to 1.15 \\
\hline IDACI d6 & $1.66^{* *}$ & 1.58 to 1.75 & $1.13^{*}$ & 1.05 to 1.22 & 0.99 & 0.87 to 1.13 & 0.97 & 0.92 to 1.02 \\
\hline IDACI d7 & $1.51 * *$ & 1.43 to 1.59 & $1.13^{* *}$ & 1.05 to 1.22 & 1.02 & 0.90 to 1.16 & 1.02 & 0.97 to 1.07 \\
\hline IDACI d8 & $1.33^{* *}$ & 1.27 to 1.41 & 1.07 & 0.99 to 1.15 & 0.92 & 0.80 to 1.04 & 0.98 & 0.93 to 1.03 \\
\hline IDACI d9 & $1.18^{* *}$ & 1.12 to 1.25 & 1.04 & 0.96 to 1.12 & 0.90 & 0.79 to 1.03 & 1.01 & 0.96 to 1.07 \\
\hline Other Black background & $0.65^{* *}$ & 0.57 to 0.73 & 1.08 & 0.90 to 1.30 & 1.32 & 0.95 to 1.84 & 1.17 & 1.03 to 1.34 \\
\hline Other ethnic group & $0.38^{* *}$ & 0.34 to 0.42 & 0.88 & 0.77 to 1.01 & 1.18 & 0.94 to 1.49 & $0.50^{* *}$ & 0.43 to 0.57 \\
\hline Other Mixed Background & $0.66^{* *}$ & 0.61 to 0.73 & 1.02 & 0.90 to 1.16 & 1.09 & 0.86 to 1.38 & 1.19 & 1.02 to 1.23 \\
\hline Other White background & $0.54^{* *}$ & 0.51 to 0.58 & $0.80^{* *}$ & 0.72 to 0.88 & 1.05 & 0.90 to 1.22 & $0.74^{* *}$ & 0.69 to 0.79 \\
\hline Bangladeshi & $0.47^{* *}$ & 0.43 to 0.53 & 1.15 & 1.02 to 1.30 & $1.46^{* *}$ & 1.18 to 1.80 & $0.43^{* *}$ & 0.38 to 0.51 \\
\hline Caribbean & $0.74^{* *}$ & 0.69 to 0.79 & 1.02 & 0.90 to 1.14 & 0.91 & 0.71 to 1.16 & 0.98 & 0.90 to 1.07 \\
\hline Chinese & $0.36^{* *}$ & 0.29 to 0.46 & 1.05 & 0.83 to 1.34 & 1.01 & 0.63 to 1.60 & 0.09 & 0.72 to 1.06 \\
\hline Gypsy/Romany & $1.94^{* *}$ & 1.68 to 2.24 & 1.22 & 0.90 to 1.64 & 1.21 & 0.65 to 2.25 & $0.32^{* *}$ & 0.19 to 0.53 \\
\hline Indian & $0.55^{* *}$ & 0.51 to 0.59 & 1.02 & 0.92 to 1.13 & 1.14 & 0.95 to 1.36 & $0.50^{* *}$ & 0.45 to 0.55 \\
\hline Irish & $0.78^{* *}$ & 0.67 to 0.91 & 0.82 & 0.63 to 1.06 & 1.15 & 0.75 to 1.74 & 0.92 & 0.77 to 1.10 \\
\hline Pakistani & $0.76^{* *}$ & 0.72 to 0.80 & $1.34^{* *}$ & 1.24 to 1.44 & $2.38^{* *}$ & 2.12 to 2.67 & $0.46^{* *}$ & 0.42 to 0.50 \\
\hline
\end{tabular}

${ }^{*} \mathrm{p}<0.01 ;{ }^{*} \mathrm{p}<0.001$.

ASD, autism spectrum disorder; FSM, free school meals; IDACI, Income Deprivation Affecting Children Index; MLD, moderate learning difficulties; PMLD, profound multiple learning difficulties; SEN, special educational needs; SEP, socio-economic position; SLD, severe learning difficulties.

when combined with the association between low cognitive ability and social position, is likely to make a contribution to the existence of social gradients in intellectual disability. ${ }^{49}$ However, the strength of this effect is highly contested. ${ }^{50}$ Resolving this issue will require the use of research designs that can help untangle the relative contribution of multiple pathways through which the intergenerational transmission of intellectual ability may occur (eg, direct genetic influences, intergenerational social influences on cognitive development and the impact of low parental intelligence on downward social mobility).

The results of the study are the first (to our knowledge) to highlight the association between area deprivation and the prevalence of less severe intellectual disability. While caution does need to be exercised, especially given the limited measurement of household-level deprivation, the results are consistent with existing literature on the impact of area-level deprivation on cognitive development. ${ }^{22}$

The results indicated that children living in lower SEP households were more likely to be identified as having ASD. This result stands in contrast to the existing literature, which has reported no evidence of social gradients in the prevalence of ASD or reverse gradients. ${ }^{16-19}$ However, the present study is the first (to our knowledge) to examine the association with household
SEP while controlling for the effects of area-level deprivation, age, gender and ethnicity. It is not possible at this stage to determine whether this reflects true variation in underlying prevalence (and, if so, whether this gradient is apparent in other countries) or whether this reflects peculiarities of the ascertainment system.

Finally, the results suggest the possible operation of identification biases in the data used. First, with a few notable exceptions, rates of identification were generally lower in children from minority ethnic communities once the effects of household SEP and area-level deprivation are taken into account. Second, rates of identification of more severe intellectual disabilities and ASD were significantly reduced in the most deprived area decile-a relationship that was strengthened when analyses were restricted to children with formal Statements of SEN. While it is possible that these results reflect true variation in the prevalence of I/DD (eg, resulting from increased child mortality rates in the most deprived communities), they may also reflect such issues as (1) increased rates of exclusion of children with SENs from state-maintained schools in the most deprived communities; (2) increased difficulties that families from deprived or minority ethnic communities may have in accessing professional support; and (3) failure of schools in the most 


\section{What is already known on this subject}

The prevalence of less severe intellectual disability is greater among children in families of lower socio-economic position. There is unclear and conflicting evidence regarding the association between socio-economic position, ethnicity and more severe intellectual disability and developmental disabilities such as autism.

\section{What does this study add}

We have shown that, when controlling for the effects of ethnicity and area-level deprivation, the prevalence of all major forms of intellectual and developmental disability is greater among children in families of lower socio-economic position. Area disadvantage is also independently associated with increased prevalence of less severe intellectual disability.

deprived communities to identify more severe forms of I/DD or acquire Statements of SEN for their pupils.

\section{Unanswered questions and future research}

Future research is required to better understand (1) the causal pathways that contribute to the observed social gradients (eg,. through the use of longitudinal genetically informed studies); (2) the salience of area or neighbourhoods to the prevalence of less severe intellectual disability; and (3) the robustness of the reported association between lower household SEP and increased prevalence of autistic spectrum disorder.

Acknowledgements This research would not have been possible without support from the Data Services Group within the Department for Education regarding use of the National Pupil Database.

Funding This research was supported by a grant from Mencap: a UK Charity supporting people with intellectual disability and their families.

Competing interests None declared.

Ethical Approval Granted by the Department for Education.

Provenance and peer review Not commissioned; externally peer reviewed.

\section{REFERENCES}

1. Leonard $\mathbf{H}$, Wen $\mathbf{X}$. The epidemiology of mental retardation: challenges and opportunities in the new millennium. Ment Retard Dev Disabil Res Rev 2002;8:117-34.

2. Roeleveld N, Zielhuis GA, Gabreels $F$. The prevalence of mental retardation: a critical review of recent literature. Dev Med Child Neurol 1997;39:125-32.

3. Fryers T. Epidemiological thinking in mental retardation: issues in taxonomy and population frequency. In: Bray NW, ed, International review of research in mental retardation. Volume 19. San Diego CA: Academic Press, 1993.

4. Simonoff E, Pickles A, Chadwick 0, et al. The Croydon Assessment of Learning Study: prevalence and educational identification of mild mental retardation. J Child Psychol Psychiatry 2006;47:828-39.

5. Einfeld S, Emerson E. Intellectual disability. In: Rutter M, Bishop D, Pine D, et al, eds. Rutter's child and adolescent psychiatry. Oxford: Blackwell, 2008.

6. van Engeland H, Buitelaar JK. Austistic spectrum disorders. In: Rutter M, Bishop D, Pine D, et al, eds. Rutter's child and adolescent psychiatry. Oxford: Blackwell, 2008.

7. Jarbrink K, Knapp M. The economic impact of autism in Britain. Autism 2001;5:7-22.

8. Leonard H, Petterson B, De Klerk N, et al. Association of sociodemographic characteristics of children with intellectual disability in Western Australia. Soc Sci Med 2005;60:1499-513.

9. Heber R. Epidemiology of mental retardation. Springfield, III: Charles C Thomas, 1970.
10. Stromme $\mathbf{P}$, Magnus P. Correlations between socioeconomic status, $I 0$ and aetiology in mental retardation: a populatio-based study of Norweigan children. Soc Psychiatry Psychiatr Epidemiol 2000;35:12-18.

11. Drews CD, Yeargin-Allsop M, Decouflé P. Variation in the influence of selected siociodemographic risk factors for mental retardation. Am J Public Health 1995:85:329-44.

12. Murphy CM, Boyle C, Schendel D, et al. Epidemiology of mental retardation in children. Ment Retard Dev Disabil Res Rev 1988;4:6-13.

13. Simonoff E, Bolton $P$, Rutter M. Mental retardation: genetic findings, clinical implications and research agenda. J Child Psychol Psychiatry 1996;37:259-80.

14. Chapman D, Scott K, Stanton-Chapman T. Public health approach to the study of mental retardation. Am J Ment Retard 2008;113:102-16.

15. Croen LA, Grether JK, Selvin S. The epidemiology of mental retardation of unknown cause. Pediatrics 2001;107:E86.

16. Newschaffer CJ, Croen LA, Daniels J, et al. The epidemiology of autism spectrum disorders. Annu Rev Public Health 2007;28:235-58.

17. Fombonne E. The changing epidemiology of autism. Appl Res Intellect Disabil 2005; 18:281-94.

18. Bhasin TK, Schendel D. Sociodemographic risk factors for autism in a US metropolitan area. J Autism Dev Disord 2007:37:667-77.

19. Baird G, Simonoff E, Pickles A, et al. Prevalence of disorders of the autism spectrum in a population cohort of children in South Thames: the Special Needs and Autism Project (SNAP). Lancet 2006;368:210-15.

20. National Equality Panel. An anatomy of economic inequality in the UK. London: Government Equalities Office, 2010.

21. Kawachi I, Berkman LF, eds. Neighborhoods and health. Oxford: Oxford University Press, 2003.

22. Leventhal T, Brooks-Gunn J. The neighbourhoods they live in: the effects of neighborhood residence on child and adolescent outcomes. Psychol Bull 2000;126:309-37.

23. Emerson $\mathbf{E}$, Azmi S, Hatton $\mathrm{C}$, et al. Is there an increased prevalence of severe learning disabilities among British Asians? Ethn Health 1997;2:317-21.

24. Emerson E, Hatton C. Response to McGrother et al. (J Intellect Disabil Res, 46, 299309) 'The prevalence of intellectual disability among South Asian communities in the UK'. J Intellect Disabil Res 2004;48:201-2.

25. Yeargin-Allsop $\mathbf{M}$, Drews CD, Decouflé $\mathbf{P}$, et al. Mild mental retardation in Black and White Children in metrolpolitan Atlanta: a case control study. Am J Public Health 1995;85:324-8.

26. Leonard H, Petterson B, Bower C, et al. Prevalence of intellectual disability in Western Australia. Paediatr Perinat Epidemiol 2003;17:58-67.

27. Croen LA, Grether JK, Selvin S. Descriptive epidemiology of autism in a California population: Who is at risk? J Autism Dev Disord 2002;32:217-24.

28. Goodman R, Richards H. Child and adolescent psychiatric presentations of secondgeneration Afro-Caribbeans in Britain. Br J Psychiatry 1995;167:362-9.

29. Department for Children Schools and Families. Children with special educational needs 2009: an analysis. London: Department for Children Schools and Families, 2009.

30. Department for Education and Skills. Special educational needs code of practice. London: Department for Education and Skills, 2001.

31. Department for Education and Skills. Data collection by type of special educational need. London: Department for Education and Skills, 2005.

32. Department for Education and Skills. SEN Toolkit. London: Department for Education and Skills, 2001.

33. Flaherty J, Veit-Wilson J, Dornan P. Poverty: the facts. London: Child Poverty Action Group, 2004.

34. Noble M, McLennan D, Wilkinson K, et al. The English indices of deprivation 2007 London: Communities and Local Government, 2008.

35. Rabe-Hesketh S, Skrondal A. Multilevel and longitudinal modelling using stata. College Station, TX: Stata Press, 2008.

36. Rutter M, Tienda M. The multiplem facets of ethnicity. In: Rutter M, Tienda M, eds Ethnicity and causal mechanisms. Cambridge: Canbridge University Press, 2005: 50-79.

37. Galobardes B, Lynch JW, Davey Smith G. Childhood socioeconomic circumstances and cause-specific mortality in adulthood: systematic review and interpretation. Epidemiol Rev 2004;26:7-21.

38. Galobardes B, Lynch JW, Davey Smith G. Is the association between childhood socioeconomic circumstances and cause-specific mortality established? Update of a systematic review. J Epidemiol Community Health 2008;62:387-90.

39. World Health Organisation. Closing the gap in a generation: health equity through action on the social determinants of health. Final report of the Commission on the Social Determinants of Health. Geneva: World Health Organisation, 2008.

40. Hanson MD, Chen E. Socioeconomic status and health behaviors in adolescence: a review of the literature. J Behav Med 2007;30:263-85.

41. Marmot M, Wilkinson RG, eds. Social determinants of health. Oxford: Oxford University Press, 2006

42. Shonkoff JP, Boyce WT, McEwen BS. Neuroscience, molecular biology, and the childhood roots of health disparities: building a new framework for health promotion and disease prevention. JAMA 2009;301:2252-9.

43. The Marmot Review. Fair society, healthy lives: strategic review of health inequalities in England Post-2010. London: The Marmot Review, 2010.

44. Emerson $\mathbf{E}$, Hatton $\mathrm{C}$. The contribution of socio-economic position to the health inequalities faced by children and adolescents with intellectual disabilities in Britain. Am J Ment Retard 2007;112:140-50. 
45. Emerson E, Hatton C. Poverty, socio-economic position, social capital and the health of children and adolescents with intellectual disabilities in Britain: a replication. J Intellect Disabil Res 2007;51:866-74.

46. Emerson $\mathbf{E}$, Hatton $\mathrm{C}$. The mental health of children and adolescents with intellectual disabilities in Britain. Br J Psychiatry 2007;191:

493-9.

47. Emerson E, Einfeld S. Emotional and behavioural difficulties in young children with and without developmental delay: a bi-national perspective. J Child Psychol Psychiatry 2010;51:583-93.
48. Emerson E, McCulloch A Graham $\mathrm{H}$, et al. Socio-economic circumstances and risk of common psychiatric disorders among parents of young children with and without early cognitive delay in the UK. Am J Intellect Dev Disabil 2010;115:30-42.

49. IASSID Special Interest Research Group on Parents and Parenting with Intellectual Disabilities. Parents labelled with Intellectual Disability: position of the IASSID SIRG on Parents and Parenting with Intellectual Disabilities. J App/ Res Intellect Disabil 2008;21:296-307.

50. Neisser U, Boodoo G, Bouchard TJ, et al. Intelligence: knowns and unknowns. Am Psychol 1996:51:77-101.

\section{Advancing} Postgraduates. Enhancing Healthcare.

The Postgraduate Medical Journal is dedicated to advancing the understanding of postgraduate medical education and training.

- Acquire the necessary skills to deliver the highest possible standards of patient care

- Develop suitable training programmes for your trainees

- Maintain high standards after training ends

Published on behalf of the fellowship for Postgraduate Medicine

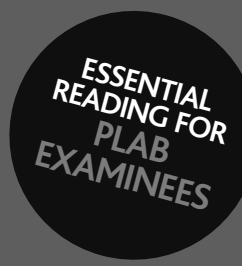

FOR MORE DETAILS OR TO SUBSCRIBE,

VISIT THE WEBSITE TODAY

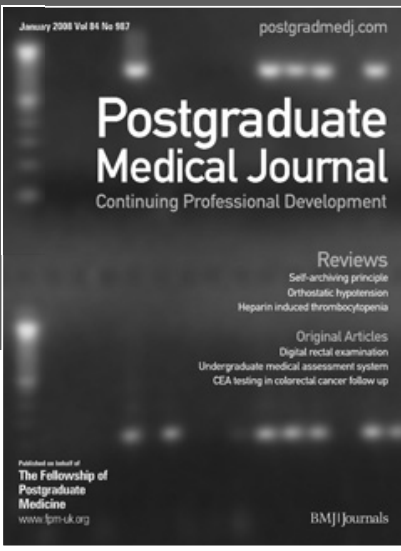

\section{postgradmedj.com}

\section{BMJIJournals}

